\title{
Socioeconomic disparities in smoking are partially explained by chronic financial stress: marginal structural model of older US adults
}

\author{
Abtin Parnia (1) , ${ }^{1}$ Arjumand Siddiqi (i) 1,2
}

\begin{abstract}
- Additional material is published online only. To view, please visit the journal online (http://dx.doi.org/10.1136/ jech-2019-213357)
\end{abstract}

${ }^{1}$ Division of Epidemiology, Dalla Lana School of Public Health, University of Toronto, Toronto, Ontario, Canada

${ }^{2}$ Department of Health Behavior, Gillings School of Global Public Health, University of North Carolina at Chapel Hill, Chapel Hill, North Carolina, USA

Correspondence to Abtin Parnia, Division of Epidemiology, Dalla Lana School of Public Health, University of Toronto, Toronto, ON M5T 3M7, Canada;

abtin.parnia@mail.utoronto.ca

Received 9 October 2019 Revised 18 November 2019 Accepted 5 December 2019 Published Online First 23 December 2019
ABSTRACT

Background A persistent socioeconomic gradient in smoking has been observed in a variety of populations. While stress is hypothesised to play a mediating role, the extent of this mediation is unclear. We used marginal structural models (MSMs) to estimate the proportion of the effect of socioeconomic status (SES) on smoking, which can be explained by an indicator of stress related to SES, experiences of chronic financial stress.

Methods Using the Health and Retirement Study (waves 7-12, 2004-2014), a survey of older adults in the USA, we analysed a total sample of 15260 people. A latent variable corresponding to adult SES was created using several indicators of socioeconomic position (wealth, income, education, occupation and labour force status). The main analysis was adjusted for other factors that influence the pathway from adult SES to stress and smoking, including personal coping resources, health-related factors, early-life SES indicators and other demographic variables to estimate the proportion of the effect explained by these pathways

Results Compared with those in the top SES quartile, those in the bottom quartile were more than four times as likely to be current smokers (rate ratio $4.37,95 \% \mathrm{Cl}$ 3.35 to 5.68). The estimate for the MSM attenuated the effect size to 3.34 (95\% Cl 2.47 to 4.52$)$. Chronic financial stress explained $30.4 \%$ of the association between adult SES and current smoking $(95 \% \mathrm{Cl} 13$ to 48).

Conclusion While chronic financial stress accounts for part of the socioeconomic gradient in smoking, much remains unexplained.

\section{INTRODUCTION}

Socioeconomic disparities in cigarette smoking are persisting despite decades of interventions. ${ }^{12}$ According to a recent review, smoking specifically contributes the greatest portion of social inequalities in health. ${ }^{3}$ Socioeconomic status (SES) affects smoking through multiple mechanisms, but tobacco control interventions have predominately focused on a limited set of determinants. ${ }^{4}$ These interventions often target modification of personal orientations to smoking, such as motivation and knowledge ${ }^{5}$ or modification of exposures to smoking cues through smoking bans and advertising. ${ }^{67}$ However, a set of empirical findings suggest that socioeconomic smoking disparities are also a function of socioeconomic differences in the psychological stress and strain of everyday life. ${ }^{8}$ Thus, a potential consequence of relying on traditional smoking interventions is that they will be insufficient for reducing socioeconomic smoking disparities because they neglect the role of stress in producing smoking behaviours. ${ }^{19}$

To date, the literature supports the prominent role of stress, ${ }^{1011}$ but the extent of mediation is not known. The complex causal relationships (multiple interconnected mediators and confounders) that describe the association between SES and smoking limit the use of common methods of mediation analysis. ${ }^{12}$ For example, the literature suggests that, in addition to stress, factors such as social support and sense of control may be operating as both confounders and mediators of stress. ${ }^{5}$ Due to this complexity, one of the assumptions of traditional mediation analysis-no confounding between mediator and outcome associated with exposure-is often unjustifiable. ${ }^{12}$ For similar reasons, structural equation modelling (SEM), which has been commonly used to investigate this question, ${ }^{13-15}$ carries restrictive assumptions regarding model specification and confounding that may be unjustifiable to study the link between SES and health behaviours with survey data. ${ }^{16}$ For instance, in a study, Martinez et al used the National Health Interviews Survey to explore several mechanisms between SES and smoking, including social cohesion, sleep disturbance, psychological distress and financial strain. ${ }^{17}$ As such, in the presence of confounding in the pathway between mediator and outcome associated with exposure (eg, social cohesion acting as a confounder of financial strain and smoking), or exposure-mediator interaction, the use of traditional mediation models and SEM can result in biassed estimates by inappropriately adjusting for the other pathways. ${ }^{18}$ Using other methods of mediation analysis can reduce some of these biases.

Building on the literature, this study attempts to answer the question of mediation by stress in the SES-smoking association using a marginal structural model (MSM), which is better able to manage these biases as it relaxes assumptions regarding the lack of association between exposure and the confounders of the mediator-outcome relationship. ${ }^{12}{ }^{19}$ In this study, we applied MSM to a longitudinal, nationally representative sample of older adults in the USA to examine how much of the association between SES and smoking is mediated by stress. More specifically, we measured the proportion of the association of SES with smoking, which can be explained by an indicator of stress related to SES, experiences of chronic financial stress. 


\section{METHODS}

\section{Study populations}

The Health and Retirement Study, a biennial, nationally representative longitudinal study of older adults in the USA, was used. ${ }^{20}$ Our sample consisted of individuals present in wave 7 (2004: baseline), as psychosocial variables were collected starting in the following wave. The psychosocial questionnaire, containing the key mediating variables of interest, was delivered to half of the sample in wave 8 and the other half in wave 9 following the same pattern of half samples for subsequent waves (ie, wave 10 for the first half sample and wave 11 for the second half sample). We included all participants who were eligible for any of the psychosocial questionnaires (excluding wave 9, as key variables were not included in that year). Based on these specifications, the total sample consisted of 15260 people who participated in wave 7 and at least one other wave, up to wave 12 (2004-2014). We used all prescribed weighting technique for complex survey design in addition to correction for missing values in the psychosocial questionnaire. ${ }^{2021}$

\section{Measures}

\section{Outcome variable}

We examined current smoking (dichotomised yes vs no) as the key outcome variable, measured in all study waves.

\section{Main exposure}

The main exposure variable was SES, as conceptualised by Nandi et $a l,{ }^{22}$ which considered both early-life and adult socioeconomic circumstances. ${ }^{22}$ These latent factors were created using maximum-likelihood confirmatory factor analysis. The adult SES factor was constructed with the following variables: household wealth and income, education, longest occupation and labour force status at baseline. The early-life SES factor was constructed based on maternal and paternal education, paternal occupation, living in the south of the USA and living in rural areas. The earlylife variable was used as a baseline adjustment for the models. The factor scores were then turned into quartiles. To reduce bias due to missing observations related to SES, we used multiple imputation in calculating factor scores based on the other variables in the model. We also explored factor analysis with fullinformation maximum likelihood estimation as an alternative strategy. Model performances for both methods were similar and are reported in online supplementary appendix A.

\section{Main mediator}

Stress was measured using a series of questions related to 'experiences of chronic stress'. ${ }^{21}$ Participants were asked to identify problems that were current and lasted 12 months or longer. We used two questions related to SES, general financial strain and housing problems. Both financial strain and housing problems have been linked to smoking in prior studies. ${ }^{23} 24$ The responses were dichotomised and recoded as yes if participants answered 'yes' to either of the questions in the measurement wave. As this measure was repeated every second wave, in waves 8-12 (though not available for wave 9), the half sample of participants who were eligible for wave 8 had two additional observations of stress, at waves 10 and 12 .

\section{Mediator outcome confounders}

Smoking behaviour is influenced by personal coping resources and, in turn, these resources are patterned by SES. ${ }^{25}$ In this analysis, we used two common personal coping resources, social support and sense of control. ${ }^{26}$
Several studies have emphasised the role of social support in mediating the relationship between SES and smoking, and between stress and smoking. ${ }^{172527}$ Two indices of social support were used to measure the perceived quality of social support, both negative and positive. Each of these measures detailed relationship with spouse, children, other family or friends. ${ }^{28}$ The responses were averaged across the relationships, creating two indices of positive and negative social support. The construct of sense of control is a key psychological determinant of SES disparities in health. ${ }^{29}$ In this analysis, two measures of control were used, perceived constraints on personal control and perceived sense of mastery, both measured by five items and averaged across the items.

\section{Exposure outcome confounders}

Being diagnosed with a condition is likely to be associated with subsequent health behaviours and thus acts as a confounder of the SES-smoking relationship. ${ }^{30} 31$ The change in health condition variables was physician diagnosis of high blood pressure, cancer, lung disease, heart problem, stroke, psychiatric condition or diabetes since the last wave of measurement. Self-rated health and drinking frequency were also included due to their close association with smoking and SES. ${ }^{3233}$

\section{Statistical analyses}

Counts, weighted percentages, weighted proportion of current smokers and missing percentage of the variables were calculated. Log-linear regression models were used to examine both segments of the pathway: the path between SES to stress, and stress and other psychosocial variables to smoking. Next, we fitted a series of models using pooled log-linear regressions (with clustered standard errors within each subject for multiple measurements) for the mediation of stress in the pathway between SES-smoking. Model 1 estimates total effect of SES on current smoking; controlling for baseline covariates include early-life SES, race, sex and age. Models 2 and 3 added the mediator and the covariates, respectively. An additional model was also fitted to check for the presence of exposure-mediator interaction (adult SES interaction with stress). Since the mediation between exposure-mediator was not significant at $\mathrm{p}<0.1$, it was not included in the analysis (online supplementary table S2). Model 3 is estimated with equation 1 :

$$
\begin{aligned}
\log \left[P \left(Y_{i t}\right.\right. & \left.\left.=1 \mid A_{i}=a, M_{i t}=m, C_{i}=c, R_{i t-1}=r, S_{i t}=s\right)\right] \\
& =\beta_{0}+\beta_{1} A_{i}+\beta_{2} M_{i t}+\beta_{3} C_{i}+\beta_{4} R_{i t-1}+\beta_{5} S_{i t}
\end{aligned}
$$

In the equation $1, Y$ represents outcome, current smoking for individual $i$ at time $t$. Symbol $A$ represents adult SES at the baseline for individual $i$. The mediator, chronic financial stress, is represented by $M$ at time $t$, as we hypothesise that the influence of stress on current smoking may be fairly immediate. The baseline covariates are represented by $C$. The time-varying confounders are health-related factors lagged by a wave (time $t-1)$ and coping resources measured at time $t$, represented by $R_{i t-1}$ and $S_{i t}$, respectively. To ensure temporal precedence, healthrelated factors were lagged. An illustration of these relationships can be found in figure 1 .

As discussed, the association of SES with the confounders of the stress-smoking relationship (ie, personal coping resources and health-related factors) invalidates the assumptions of traditional methods of mediation analysis. Thus, equation 1 provides a biassed estimate of the controlled direct effect (CDE). Model 4 is the MSM with inverse-probability weights. The details of this method are described in online supplementary appendix A and are reported in the literature. ${ }^{19} 34$ Briefly, this method reweights 


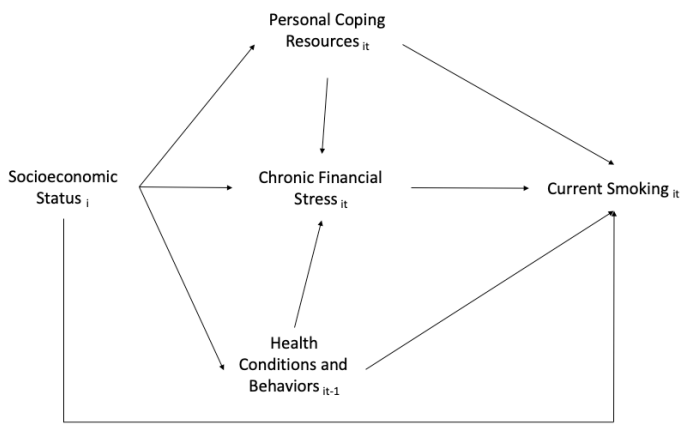

Figure 1 Illustration of the conceptual relationships between the variables in the study and the time of measurement.

the study population to a pseudo-population, based on the likelihood of each participant receiving their observed exposure and mediator values, conditional on the predictors of exposure and mediator (ie, the predicted probabilities of a model for the exposure and a model for the mediator). As a result, a counterfactual comparison is generated to estimate the association in the absence of the effect of mediator. The inverse-probability weights - stabilised as recommended by Cole and Hernan ${ }^{35}$ was constructed for the stress and the adult SES measures to be used in the reweighting required for MSM. ${ }^{35}$ Model 4 is estimated using equation 2 :

$\log \left[P\left(Y_{i t}=1 \mid A_{i}=a, M_{i t}=m\right)\right]=\beta_{0}+\beta_{1} A_{i}+\beta_{2} M_{i t}$

In this equation, the CDE is estimated by the value of $\beta_{1}$. Following the MSM, we calculated the proportion of the effect explained by the stress pathway. This measure is calculated by equation 3, described in VanderWeele. ${ }^{36}$

Proportion Eliminated $=\frac{(R R(\text { Total Effect })-R R(C D E(m)))}{R R(\text { Total Effect })-1}$

We calculated the proportion eliminated for the difference between each quantile of income and used bootstrapping method with 1500 resampling to calculate the 95 th percentile CIs. The analysis was done using $\mathrm{R}$ and STATA 14.2.

\section{Sensitivity analyses}

Sensitivity analysis was conducted to explore the various assumptions on mediating and moderating relationships, measurement error and unmeasured confounding. We explored the role of the coping resources variables, as the personal coping variables can act as mediators or moderators of the relationship between stress and smoking. By including interaction terms for the coping resources with SES and with stress, the role of these factors in moderating the SES-smoking and SES-stress relationships was tested. Furthermore, social support and sense of control have mediating roles in association between SES and smoking. ${ }^{29} 37$ Hence, models were created to examine the role of each mediators independently as well as the three mediators combined together.

The effect of missing observations of the inference of the study was tested by including a missing category for stress. Lastly, as this inference is based on an observational study, there is a likelihood of unmeasured confounding that can affect the results. To quantify the likely impact of this problem, we have calculated $\mathrm{E}$ values, as proposed by VanderWeele and Ding, ${ }^{38}$ to measure the minimum strength of association for a confounder that can shift the estimate to null effect. ${ }^{38}$

\section{RESULTS}

Table 1 details the distribution of the variables in the study. To capture the entire sample, the first measurement for timevarying variables is used. Online supplementary tables S1.1-S1.4 are the observations in the sample by each wave. The weighted prevalence of smoking in the overall sample was $13.47 \%(95 \%$ CI $12.5 \%$ to $14.5 \%)$. This prevalence is lower than $18.1 \%(95 \%$ CI $17.4 \%$ to $18.7 \%$ ), the national current smoking prevalence in 2004 (as the sample is weighted to 2004 population) for US adults above 45 years old. ${ }^{39}$ The missing observations in most variables is below $5 \%$, with the exception of psychosocial variables, where missingness is closer to $18 \%$.

Tables 2 and 3 describe the associations between SES and psychosocial variables, and these variables and smoking, respectively. As expected, compared with study participants in the top quartile of adult SES (most advantageous) category, those in the bottom quartile of SES (least advantageous) had 2.29 times (95\% CI 2.09 to 2.50) higher likelihood of having experienced chronic financial stress. Moreover, in table 3, the likelihood of being a current smoker is $36 \%$ (95\% CI 22\% to 52\%) higher in those who experienced chronic financial stress compared with those who did not.

Table 4 details the results of the mediation models. Model 1 estimates that those in the top quartile of adulthood SES compared with the bottom quartile of adulthood SES have 4.37 (95\% CI 3.35 to 5.68) times higher likelihood of being current smokers, with decreasing magnitude for other quartiles. Models 2 and 3 demonstrate an attenuation of the effect size with the addition of stress and other covariates in the model. In model 3, the effect of experience of chronic financial stress is 1.13 (95\% CI 1.01 to 1.26$)$, which is attenuated compared with model 2 . The CDE for the comparison between the top quartile of adulthood SES and the bottom quartile is 3.34 (95\% CI 2.47 to 4.52 ). Overall, for various categories of adulthood SES, around one-third of the association between adulthood SES and current smoking was explained by the chronic financial stress pathway.

Results of sensitivity analysis indicates lack of moderation by personal coping resources. The exploration of multiple mediation pathways shows that the combined use of all psychosocial variables results in the largest attenuation of the effect. However, when exploring pathways independently, the largest estimate is for the financial chronic stress mediation pathway. The results of the sensitivity analysis are reported in online supplementary tables S4-S7.

To account for the likelihood of unmeasured confounders, we calculated E-values for our total effect measurements and measurements of CDE. The full results are provided in online supplementary table S8. The calculations suggest that the minimum strength of an unmeasured confounder for the comparison of the bottom to top quartiles of adulthood SES to be null is 6.1 (4.4 to 8.5 for the $95 \%$ CI of the estimate).

\section{DISCUSSION}

This study examined the mediation of chronic financial stress in the association between SES and smoking. By addressing major biases produced in previous studies, which used more traditional mediation analysis techniques, this study builds on the literature that explains how health behaviours are shaped. 
Table 1 Descriptive statistics of the variables, $N=15260$

\begin{tabular}{|c|c|c|c|c|c|}
\hline Variables & Level & Count & Weighted \% & Weighted \%, smokers & $95 \% \mathrm{Cl}$ \\
\hline \multirow[t]{2}{*}{ Sex } & Male & 6268 & 45.26 & 15.04 & 13.82 to 16.26 \\
\hline & Female & 8992 & 54.74 & 12.04 & 10.97 to 13.12 \\
\hline \multirow{2}{*}{ Race } & Black & 2136 & 10.67 & 17.96 & 15.78 to 20.14 \\
\hline & Other & 796 & 5.53 & 17.09 & 12.93 to 21.24 \\
\hline \multirow[t]{3}{*}{ Early-life SES } & $<25$ th & 3471 & 20.11 & 15.67 & 14.11 to 17.23 \\
\hline & 50th-75th & 3961 & 26.63 & 13.64 & 12.23 to 15.06 \\
\hline & $<75$ th & 4190 & 31.31 & 11.58 & 10.05 to 13.11 \\
\hline \multirow[t]{3}{*}{ Adulthood SES } & $<25$ th & 3353 & 19.6 & 19.18 & 17.49 to 20.86 \\
\hline & 25th-50th & 3704 & 22.99 & 16.08 & 14.17 to 17.99 \\
\hline & 50th-5th & 3978 & 25.79 & 13.43 & 11.61 to 15.25 \\
\hline \multirow{2}{*}{ Age } & $65-75$ & 4930 & 23.52 & 9.451 & 8.317 to 10.72 \\
\hline & $75+$ & 2891 & 16.23 & 3.87 & 3.048 to 4.902 \\
\hline \multirow[t]{6}{*}{ Self-rated health } & 1. Excellent & 1485 & 10.74 & 6.93 & 5.32 to 8.54 \\
\hline & 2. Very good & 4448 & 30.35 & 10.32 & 8.83 to 11.81 \\
\hline & 3. Good & 4795 & 30.59 & 13.66 & 12.57 to 14.74 \\
\hline & 4. Fair & 3245 & 20.11 & 18.29 & 16.12 to 20.47 \\
\hline & 5. Poor & 1267 & 8.12 & 20.3 & 17.47 to 23.12 \\
\hline & Missing & 20 & 0.1 & & \\
\hline \multicolumn{6}{|l|}{ Change in conditions } \\
\hline Diabetes & $0=$ no & 14806 & 96.96 & 13.5 & 12.44 to 14.56 \\
\hline Lung disease & Missing & 34 & 0.16 & & \\
\hline \multirow[t]{3}{*}{ Heart disease } & $0=$ no & 14691 & 96.39 & 13.48 & 12.43 to 14.52 \\
\hline & $1=$ yes & 544 & 3.45 & 11.02 & 7.58 to 14.46 \\
\hline & Missing & 25 & 0.16 & & \\
\hline \multirow[t]{3}{*}{ Stroke } & $0=$ no & 14977 & 98.36 & 13.43 & 12.43 to 14.43 \\
\hline & $1=y e s$ & 266 & 1.56 & 11.31 & 6.83 to 15.79 \\
\hline & Missing & 17 & 0.08 & & \\
\hline \multirow[t]{3}{*}{ Psychiatric condition } & $0=$ no & 14891 & 97.61 & 13.33 & 12.34 to 14.33 \\
\hline & $1=$ yes & 337 & 2.21 & 16.24 & 10.55 to 21.92 \\
\hline & Missing & 32 & 0.17 & & \\
\hline \multirow[t]{5}{*}{ Number of drinks in a day } & 0 or none & 10218 & 64.23 & 12.56 & 11.44 to 13.68 \\
\hline & 1 or 2 & 3982 & 27.32 & 9.67 & 8.52 to 10.81 \\
\hline & 3 or 4 & 749 & 5.79 & 28.61 & 23.90 to 33.33 \\
\hline & 5 or more & 272 & 2.34 & 38.12 & 31.27 to 44.98 \\
\hline & Missing & 39 & 0.31 & & \\
\hline \multirow[t]{3}{*}{ Chronic stress } & $0=$ no & 7412 & 46.87 & 10.02 & 9.16 to 10.95 \\
\hline & $1=$ yes & 4888 & 33.48 & 16.72 & 15.03 to 18.56 \\
\hline & Missing & 2960 & 19.65 & 16.14 & 14.34 to 18.12 \\
\hline Social support, positive & Below 50th & 6412 & 43.21 & 14.58 & 13.10 to 16.06 \\
\hline
\end{tabular}




\begin{tabular}{|c|c|c|c|c|c|}
\hline Variables & Level & Count & Weighted \% & Weighted \%, smokers & $95 \% \mathrm{Cl}$ \\
\hline & Missing & 2530 & 17.14 & 16.47 & 14.44 to 18.50 \\
\hline \multirow{2}{*}{ Social support, negative } & Above 50th & 5937 & 39.92 & 14.6 & 13.19 to 16.01 \\
\hline & Missing & 2524 & 17.11 & 16.44 & 14.42 to 18.47 \\
\hline Sense of control, mastery & Missing & 2706 & 18.26 & 16.05 & 14.13 to 17.97 \\
\hline \multirow[t]{3}{*}{ Sense of control, constraints } & Below 50th & 7005 & 46.27 & 10.98 & 9.84 to 12.11 \\
\hline & Above 50th & 5536 & 35.41 & 15.23 & 13.63 to 16.83 \\
\hline & Missing & 2719 & 18.31 & 15.98 & 14.07 to 17.89 \\
\hline
\end{tabular}

Based on a nationally representative sample of older adults in the USA, our study estimates that one-third of the socioeconomic disparity in current smoking is explained by underlying differences in the experience of chronic financial stress. Notably, our results also suggest that the majority of the association between adult SES and current smoking remains unexplained by our model, which included most of the variables that have been implicated in prior literature.

Other studies that have explored the role of financial stress in various populations show strong effect on smoking as well. Most studies have not included similar mediation analysis and therefore are not directly comparable. Some studies have stratified their samples by income and education or have only sampled low SES population. For instance, Guillaumier et al ${ }^{40}$ demonstrate twice the odds of experiencing financial strain in

\section{Table 2 Association between adulthood SES, personal coping} resources and financial chronic stress

\begin{tabular}{|lll}
\hline & \multicolumn{2}{l}{ Chronic financial stress } \\
\cline { 2 - 3 } & \multicolumn{2}{l}{ Rate ratio } \\
\hline Adulthood SES & & $1.88^{* * *}$ \\
\hline$<25$ th quartile (most disadvantageous) & $2.29^{* * *}$ & $(1.72$ to 2.06$)$ \\
\hline & $(2.09$ to 2.50$)$ & $1.69^{* * *}$ \\
\hline 25th-50th & $1.91^{* * *}$ & $(1.57$ to 1.83$)$ \\
\hline 50 th-75th & $(1.76$ to 2.07$)$ & $1.39^{* * *}$ \\
\hline 75th quartile (least disadvantageous) & 1 & $(1.29$ to 1.49$)$ \\
\hline (ref) & $1.48^{* * *}$ & 1 \\
\hline Sense of Control Scale & $(1.37$ to 1.59$)$ & \\
\hline Mastery & & $0.94^{* * *}$ \\
\hline Constraints & & $(0.92$ to 0.95$)$ \\
\hline Social Support Scale & $1.13^{* * *}$ \\
\hline Positive & $(1.11$ to 1.15$)$ \\
\hline Negative & & \\
\hline
\end{tabular}

Models are adjusted for baseline covariates: age, sex, early-life SES and race. Rate ratio; $95 \% \mathrm{Cl}$ in parentheses.

Person-wave $=19918, \mathrm{~N}=11778$.

${ }^{*} \mathrm{P}<0.05,{ }^{* *} \mathrm{P}<0.01,{ }^{* * *} \mathrm{P}<0.001$

ref, reference; SES, socioeconomic status. low SES smokers compared with low SES non-smokers. ${ }^{40}$ In a study by Grafova, ${ }^{23}$ financial strain was investigated and found a higher likelihood of being smoker for the lowest income quartile compared with the highest (for men $17.66 \%$ vs $3.28 \%$ and for women $5.1 \%$ vs $3.6 \%) .{ }^{23}$ Lastly, Shaw et al also found interaction effects between financial strain and education, in the direction of higher smoking likelihood in low SES groups with financial strain. ${ }^{41}$ Based on these studies, our findings are in line with the strong effect of chronic financial stress in explaining smoking disparities by SES. Our results also converged with those of Martinez et al, ${ }^{17}$ who used SEM to explore a similar question on the pathways that mediate SES effects on smoking. ${ }^{17}$ Martinez et $a l^{17}$ found that the four pathways (including financial strain) they examined accounted for one-third of the effect of SES on current smoking, while the remaining two-thirds of the effect of SES remains unexplained by the pathways studied. ${ }^{17}$ When they specifically examined mediation by the financial strain pathway, they found the indirect effect of this pathway to be $26 \%$ of the total effect of SES on smoking. Both studies confirm the major role of financial strain in the mediation of SES and smoking association as well as the large unexplained effect in the differences in smoking rates.

Table 3 The association between psychosocial factors and current smoking

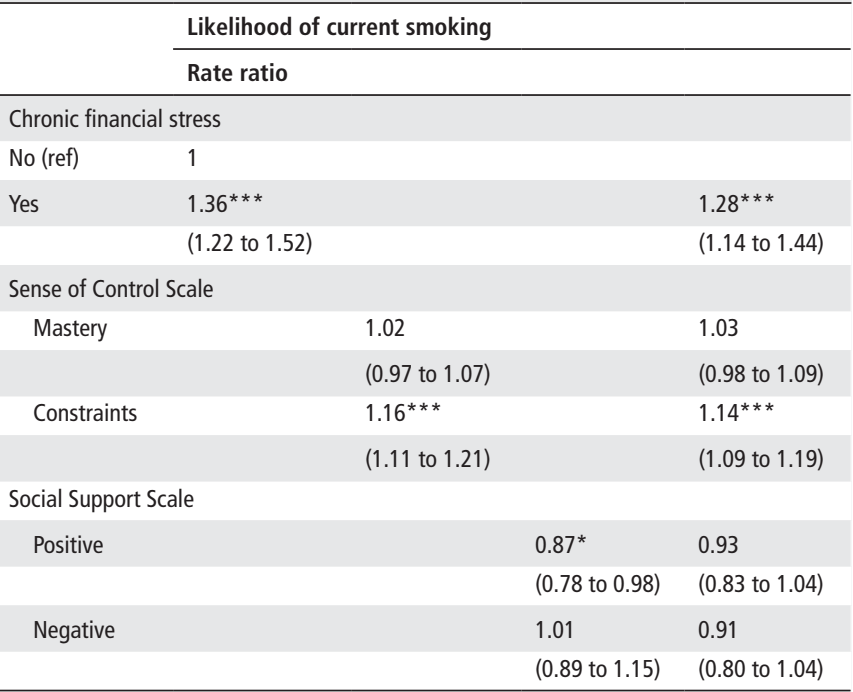

Person-wave $=19918 ; \mathrm{N}=11778$.

${ }^{*} \mathrm{P}<0.05,{ }^{* *} \mathrm{P}<0.01,{ }^{* * *} \mathrm{P}<0.001$

ref, reference. 
Table 4 Rate ratio of smoking and mediation by chronic financial stress ( $N=11778 /$ person-wave $=19918)$

\begin{tabular}{|c|c|c|c|c|c|}
\hline Models & 1 & 2 & 3 & 4 & Proportion explained \\
\hline \multicolumn{6}{|l|}{ Adult SES } \\
\hline \multirow{2}{*}{$\begin{array}{l}<25 \text { th quartile (most } \\
\text { disadvantageous) }\end{array}$} & $4.366^{* * *}$ & $4.103^{* * *}$ & $3.178^{* * *}$ & $3.343^{* * *}$ & $0.304^{* * *}$ \\
\hline & (3.354 to 5.683 ) & (3.150 to 5.343 ) & (2.428 to 4.160$)$ & (2.472 to 4.520$)$ & (0.132 to 0.476$)$ \\
\hline \multirow[t]{2}{*}{ 25th-50th } & $3.091 * * *$ & $2.944^{* * *}$ & $2.529 * * *$ & $2.324^{* * *}$ & $0.367^{* * *}$ \\
\hline & (2.443 to 3.911$)$ & (2.328 to 3.723 ) & (1.991 to 3.213 ) & (1.736 to 3.109 ) & (0.204 to 0.529$)$ \\
\hline $\begin{array}{l}>75 \text { th quartile (least } \\
\text { disadvantageous) (ref) }\end{array}$ & 1 & 1 & 1 & 1 & \\
\hline \multicolumn{6}{|l|}{ Chronic stress } \\
\hline No & & 1 & 1 & 1 & \\
\hline Yes & & $1.188^{* *}$ & $1.126^{*}$ & $1.247^{* *}$ & \\
\hline Mastery & & & (0.997 to 1.102 ) & & \\
\hline \multirow[t]{2}{*}{ Constraints } & & & $1.075^{* *}$ & & \\
\hline & & & (1.026 to 1.127 ) & & \\
\hline \multicolumn{6}{|l|}{ Social support } \\
\hline \multirow[t]{2}{*}{ Positive } & & & 0.886 & & \\
\hline & & & (0.781 to 1.004$)$ & & \\
\hline \multirow[t]{2}{*}{ Negative } & & & 0.946 & & \\
\hline & & & (0.851 to 1.052 ) & & \\
\hline
\end{tabular}

Rate ratio; $95 \% \mathrm{Cl}$ in parentheses.

Model 1 is adjusted for baseline variables, namely, age, sex, race, early-life SES.

Model 2 is adjusted for baseline variables and chronic financial stress.

Model 3 is model 2 with additional adjustments for baseline variables and time-varying confounders.

Model 4 is a marginal structural model estimating the controlled direct effect using inverse probability weighting.

${ }^{*} \mathrm{P}<0.05,{ }^{*} \mathrm{P}<0.01,{ }^{*}{ }^{*} \mathrm{P}<0.001$

ref, reference; SES, socioeconomic status.

There are several limitations to this study. As the population for this study is older adults in the USA, there is potential for selection bias that under-represents smokers and those of low SES who experience earlier mortality. ${ }^{20}$ For instance, the proportion of deaths in the follow-up from 2004 to 2014 is twice as much in the smokers in the low SES category compared with smokers in the high SES category (weighted \% of deaths among smokers, $<25$ th percentile $\mathrm{SES}=\% 41.18,>75$ th percentile $\mathrm{SES}=\% 12.45$ ). This type of selection bias can result in underestimation of the coefficients, so our study is likely a conservative estimate of the SES gradient in smoking. The large percentage of missing values in the coping resources and stress variables may also have had an impact on our results, as weighted proportion of missing from these variables is between $15 \%$ and $20 \%$ and may not be missing at random. However, our analysis investigating the impact of missing values in the mediator variable produced similar results, by using a missing category in the measurement of chronic stress (online supplementary table B3 in appendix B), suggesting that the effect size observed in this analysis is likely unaffected by the missingness in the main mediation variable. Furthermore, the application of the non-response adjustment factor to the survey weights reduces some of the potential biases. $^{21}$

The strength of this study is in the use of MSM with inverse probability weighting for mediation analysis. As this method does not have the strict assumptions of SEM, and the potential bias resulted from the use of traditional mediation methods due to the association between exposure and the confounders of the mediator-outcome relationship. ${ }^{12} 18$ The findings of our study suggest that chronic financial stress plays a large role in mediating the association between SES and smoking. It also suggests that SES shapes our behaviours through other means not associated with chronic financial stress.

The basis of the variables selected in this study is described in detail in online supplementary appendix A. Briefly, the conceptual framework of Harwood et $a l^{25}$ includes most of the variables included in this study. ${ }^{25}$ Hiscock et al discuss the possibility of other mechanism underlying SES disparities in smoking. ${ }^{2}$ These factors include health literacy, access to cessation resources, peer influence or tobacco company marketing. These pathways were unaccounted for in this study due to limitations of the survey used, so it is possible that they accounted for the remaining (unexplained) effects of adult SES on smoking yielded by our analyses. However, other studies that have explored the role of health literacy pathway or factors associated with cessation resources suggest these factors may only explain a small amount of the association. $^{242}$ Future research can further explore the large unexplained portion of the link between SES and smoking. 


\section{What is already known on this subject}

- Cigarette smoking rates are much higher in those with disadvantageous socioeconomic conditions. Stress likely contributes to these differences, but the extent of this contribution is not clear. There have been studies on this topic, but they have either not used robust methods or omitted important factors.

\section{What this study adds}

- By using robust statistical methods and accounting for variables related to stress, this study estimated that approximately one-third of socioeconomic disparities in smoking for older adults can be explained by the experience of financial stress. Knowing how much financial stress influences the disparities in smoking rates can help public health interventions assess their priorities for reducing health inequities.

Acknowledgements The authors thank Odmaa Sod-Erdene, Faraz Vahid Shahidi and Chantel Ramraj for their critical comments and resources in the process of conducting this research.

Contributors AP conceived and planned the study in discussion with AS. AP conducted the data analysis. AP and AS discussed the analysis and interpreted the findings. AP drafted the manuscript. AS edited the manuscript. AS supervised the project.

Funding This research was supported by Canada Research Chair in Population Health Equity awarded to Dr Siddiqi by the Canadian Institutes of Health Research.

Competing interests None declared.

Patient consent for publication Not required.

Ethics approval Our study drew on secondary, publicly available data and was thus exempt from ethics approval, as stipulated in Article 2.2 of the Tri-Council Policy Statement: Ethical Conduct of Research Involving Humans - TCPS 2 (2018),

Provenance and peer review Not commissioned; externally peer reviewed.

Data availability statement Data are available in a public, open access repository. The data used in this study are available through the Health and Retirement Study website (https://hrs.isr.umich.edu/).

\section{ORCID iDs}

Abtin Parnia http://orcid.org/0000-0003-4321-3260

Arjumand Siddiqi http://orcid.org/0000-0002-2458-9011

\section{REFERENCES}

1 Fleary SA, Nigg CR, Freund KM. An examination of changes in social disparities in health behaviors in the US, 2003-2015. Am J Health Behav 2018:42:119-34.

2 Hiscock R, Bauld L, Amos A, et al. Socioeconomic status and smoking: a review. Ann N Y Acad Sci 2012;1248:107-23.

3 Petrovic D, de Mestral C, Bochud M, et al. The contribution of health behaviors to socioeconomic inequalities in health: a systematic review. Prev Med 2018;113:15-31.

4 Brown T, Platt S, Amos A. Equity impact of population-level interventions and policies to reduce smoking in adults: a systematic review. Drug Alcohol Depend 2014;138:7-16.

5 Sorensen G, Barbeau E, Hunt MK, et al. Reducing social disparities in tobacco use: a social-contextual model for reducing tobacco use among blue-collar workers. Am J Public Health 2004:94:230-9.

6 Parks MJ, Kingsbury JH, Boyle RG, et al. Behavioral change in response to a statewide tobacco Tax increase and differences across socioeconomic status. Addict Behav 2017;73:209-15.

7 Seidenberg AB, Caughey RW, Rees VW, et al. Storefront cigarette advertising differs by community demographic profile. Am J Health Promot 2010;24:e26-31.

8 Beckie TM. A systematic review of allostatic load, health, and health disparities. Biol Res Nurs 2012;14:311-46.

9 Bickel WK, Moody L, Quisenberry AJ, et al. A competing neurobehavioral decision systems model of SES-related health and behavioral disparities. Prev Med 2014;68:37-43.
10 Slopen N, Dutra LM, Williams DR, et al. Psychosocial stressors and cigarette smoking among African American adults in midlife. Nicotine Tob Res 2012;14:1161-9.

11 Siahpush M, Carlin JB, stress F. Financial stress, smoking cessation and relapse: results from a prospective study of an Australian national sample. Addiction 2006;101:121-7.

12 Naimi Al, Schnitzer ME, Moodie EEM, et al. Mediation analysis for health disparities research. Am J Epidemiol 2016;184:315-24.

13 Businelle MS, Kendzor DE, Reitzel LR, et al. Pathways linking socioeconomic status and postpartum smoking relapse. Ann Behav Med 2013;45:180-91.

14 Honjo K, Tsutsumi A, Kawachi I, et al. What accounts for the relationship between social class and smoking cessation? results of a path analysis. Soc Sci Med 2006;62:317-28.

15 Manfredi C, Cho YI, Crittenden KS, et al. A path model of smoking cessation in women smokers of low socio-economic status. Health Educ Res 2007;22:747-56.

16 Kaufman JS, Maclehose RF, Kaufman S. A further critique of the analytic strategy of adjusting for covariates to identify biologic mediation. Epidemiol Perspect Innov 2004;1:4.

17 Martinez SA, Beebe LA, Thompson DM, et al. A structural equation modeling approach to understanding pathways that connect socioeconomic status and smoking. PLoS One 2018;13:e0192451.

18 VanderWeele TJ. Mediation analysis: a practitioner's guide. Annu Rev Public Health 2016:37:17-32.

19 Richiardi L, Bellocco R, Zugna D. Mediation analysis in epidemiology: methods, interpretation and bias. Int J Epidemiol 2013:42:1511-9.

20 Servais MA. Overview of Hrs public data files for cross-sectional and longitudinal analysis. Ann Arbor MI Surv Res Cent Inst Soc Res 2010.

21 Smith J, Fisher G, Ryan L, et al. Psychosocial and lifestyle questionnaire. Surv Res Cent Inst Soc Res 2013.

22 Nandi A, Glymour MM, Subramanian SV. Association among socioeconomic status, health behaviors, and all-cause mortality in the United States. Epidemiology 2014;25:170-7.

23 Grafova IB. Financial strain and smoking. J Fam Econ Issues 2011;32:327-40.

24 Stahre M, VanEenwyk J, Siegel P, et al. Housing insecurity and the association with health outcomes and unhealthy behaviors, Washington state, 2011. Prev Chronic Dis 2015;12:E109.

25 Harwood GA, Salsberry P, Ferketich AK, et al. Cigarette smoking, socioeconomic status, and psychosocial factors: examining a conceptual framework. Public Health Nurs 2007;24:361-71.

26 Thoits PA. Stress, coping, and social support processes: where are we? what next? J Health Soc Behav 1995; Spec No:53-79.

27 Thoits PA. Mechanisms linking social ties and support to physical and mental health. Health Soc Behav 2011:52:145-61.

28 Schuster TL, Kessler RC, Aseltine RH. Supportive interactions, negative interactions, and depressed mood. Am J Community Psychol 1990;18:423-38.

29 Lachman ME, Weaver SL. The sense of control as a moderator of social class differences in health and well-being. J Pers Soc Psychol 1998;74:763-73.

30 Honda K. Psychosocial correlates of smoking cessation among elderly ever-smokers in the United States. Addict Behav 2005:30:375-81.

31 Quiñones AR, Nagel CL, Newsom JT, et al. Racial and ethnic differences in smoking changes after chronic disease diagnosis among middle-aged and older adults in the United States. BMC Geriatr 2017;17:48.

32 Moon SS, Kang S-Y, Jitpitaklert W, et al. Decision tree models for characterizing smoking patterns of older adults. Expert Syst Appl 2012;39:445-51.

33 Bonevski B, Regan T, Paul C, et al. Associations between alcohol, smoking, socioeconomic status and comorbidities: evidence from the 45 and up study. Drug Alcohol Rev 2014;33:169-76.

34 Brumback BA, Bouldin ED, Zheng HW, et al. Testing and estimating Model-Adjusted Effect-Measure modification using marginal structural models and complex survey data. Am J Epidemio/ 2010;172:1085-91.

35 Cole SR, Hernán MA. Constructing inverse probability weights for marginal structural models. Am J Epidemiol 2008;168:656-64.

36 VanderWeele TJ. Policy-Relevant proportions for direct effects. Epidemiology 2013:24:175-6.

37 Chou K-L, Chi I, Events SL. Stressful life events and depressive symptoms: social support and sense of control as mediators or Moderators? Int J Aging Hum Dev 2001:52:155-71.

38 VanderWeele TJ, Ding P. Sensitivity analysis in observational research: introducing the E-Value. Ann Intern Med 2017:167:268-74.

39 NCHS. National health interview survey (NHIS). National Center for Health Statistics, 2004.

40 Guillaumier A, Twyman L, Paul C, et al. Financial stress and smoking within a large sample of socially disadvantaged Australians. Int J Environ Res Public Health 2017:14:231.

41 Shaw BA, Agahi N, Krause N. Are Changes in Financial Strain Associated With Changes in Alcohol Use and Smoking Among Older Adults?*. J Stud Alcohol Drugs 2011;72:917-25.

42 Stewart DW, Adams CE, Cano MA, et al. Associations between health literacy and established predictors of smoking cessation. Am J Public Health 2013;103:e43-9. 